\title{
TRABALHADORES MAIS VELHOS E ENVELHECIMENTO ATIVO NA EUROPA*
}

\author{
Alan Walker**
}

\section{Resumo}

Este artigo enfatiza a necessidade urgente de políticas públicas ativas na preparação para o envelhecimento da força de trabalho e para reduzir os custos de previdência social. As iniciativas entre os Países Membros da União Européia no que se refere a cuidar do paradoxo idade/emprego ainda são bastante tímidas, principalmente se restringindo a subsídios para saída precoce. Recentes estudos europeus mostraram que ainda existe somente uma minoria de organizações que desenvolveram iniciativas para se ajustar ao envelhecimento da força de trabalho, entre estes, porém, de autoridades públicas e companhias comerciais altamente prestigiadas da Europa. Além disso, nossa pesquisa ilustrou um número de maneiras práticas pelas quais as outras organizações podem administrar o envelhecimento de suas forças de trabalho de modo mais eficiente. Há também sinais na mudança de postura entre os parceiros sociais. Desta forma, podemos observar a existência de oportunidades na Europa para assegurar que o envelhecimento da força de trabalho não limita o potencial de trabalho dos indivíduos envolvidos e nem a competitividade econômica das empresas. O que se faz necessário é uma estratégia em nível de União Européia para um envelhecimento ativo a partir de ações positivas já iniciadas.

Palavras-chave: Envelhecimento. Trabalhadores mais Velhos. Políticas Públicas.

\footnotetext{
Tradução: Gustavo Caetano de Mattos Mano; revisão: professor doutor Johannes Doll, coordenador do Núcleo de Estudos Interdisciplinares sobre o Envelhecimento da Universidade Federal do Rio Grande do Sul (UFRGS). E-mail: johannes.doll@ufrgs.br

** Professor de Política Social da Universidade de Sheffield, Reino Unido. E-mail: a.c.walker@sheffield.ac.uk
} 


\section{Introdução}

O envelhecimento populacional afeta todas as regiões do mundo. Para aqueles países com um sistema de pensões estabelecido, particularmente os financiados por pay-as-you-go (PAYG) ${ }^{1}$, a extensão da longevidade e o declínio da fertilidade têm levantado questões sobre a sustentabilidade futura. Algumas vezes estas questões têm sido colocadas em termos alarmistas como o "crescente fardo da dependência" ou a "crise da terceira idade". Tal argumento apareceu somente poucas vezes na União Européia (UE) e, certamente, não se compara com a discussão pública que ocorreu nos Estados Unidos da América (EUA), em meados da década de 80, sobre eqüidade geracional. As respostas dos políticos da UE ao impacto do envelhecimento populacional nos sistemas previdenciários, tanto nos EUA como na UE, têm sido ajustes relativamente modestos em suas fórmulas pensionais (geralmente estendendo o número de anos de contribuição) ou incentivando a previdência privada. A mudança política radical no Reinado Unido nos anos 80 - a troca substancial de PAYG público para capitalização privada, foi trazida por motivos ideológicos e não foi reproduzida em outros países da UE.

Até pouco tempo, os políticos dos países membros da UE focavam suas atenções principalmente nos primeiros três pilares da aposentadoria (pública, privada e ocupacional). É surpreendente o pequeno enfoque que o quarto pilar, emprego, tem nos debates sobre a sustentabilidade do sistema previdenciário. O que ocorre normalmente é que economistas fazem projeções sobre 'proporções de dependência' baseadas nas hipóteses, ceteris paribus, de que as condições existentes, como as taxas de emprego entre diferentes faixas etárias, permanecem estáticas.

Nos últimos anos, entretanto, os políticos começaram a enfatizar a importância do emprego na idade avançada e, na UE, o conceito de envelhecimento ativo começou a tomar forma e ser reconhecido como uma prioridade política. O propósito principal deste artigo é explicar porque esta ênfase no envelhecimento ativo está emergindo e por que ele é importante. Eu vou destacar as cinco principais razões de por que os políticos estão centrados no envelhecimento ativo. Adiante, argumentarei que, pelo menos por enquanto, as ações nos países membros da UE têm sido mais passivas e

\footnotetext{
${ }^{1}$ Nota do revisor: este sistema, também conhecido como contrato de gerações, significa que as aposentadorias são pagas pelas contribuições daqueles que trabalham.
} 
que políticas públicas ativas são necessárias para se criar um envelhecimento ativo.

Antes que isso possa acontecer, todavia, a discriminação por causa da idade precisa ser superada, por representar uma barreira para o envelhecimento ativo. Ao final, sustentarei que uma administração compreensiva do envelhecimento/estratégia de envelhecimento ativo é necessária dentro de organizações, mas também em nível nacional nos países da UE, se a Europa quiser se ajustar com sucesso ao envelhecimento de sua força de trabalho e continuar competitiva em termos globais. Na conclusão, enfatizarei que, embora eu enfoque principalmente as políticas públicas, o envelhecimento da força de trabalho é uma preocupação de todos que estão envolvidos com o mercado de trabalho da UE. Não é algo que possa ser deixado para o setor público ou para o setor privado, para indivíduos ou organizações, empresas ou trabalhadores, mas requer respostas firmes de todos esses elementoschave.

\section{Fatores por trás do Enfoque Político no Envelhecimento Ativo}

O conceito de "envelhecimento ativo" está emergindo nas discussões gerontológicas e possui grande importância, especialmente em relação ao envelhecimento da força de trabalho. Nesta parte, destacarei as cinco principais razões por que os políticos estão centrando sua atenção a este conceito.

\subsection{Envelhecimento da Força de Trabalho}

A primeira razão pela qual os políticos começaram a enfatizar o envelhecimento ativo é o reconhecimento do fato de que o envelhecimento da população significa que a força de trabalho está envelhecendo e continuará a envelhecer. Como resultado do contínuo declínio da natalidade há um aumento na média de idade da população economicamente ativa em todos os países da UE. Durante os próximos dez anos, a estrutura etária da população em idade de trabalho mudará significativamente: o número de jovens (15-19 anos) diminuirá em quase um milhão (-5\%) e aqueles com idades entre 20-29 anos vão cair em nove milhões (-17\%), enquanto a categoria entre 55-59 anos crescerá 5.5 milhões (+12\%) e o grupo entre 60 64 anos aumentará em um milhão. Junto com a crescente participação da 
mulher no trabalho, essa é a mais importante mudança na composição da força de trabalho européia no último século.

Com pouquíssimas exceções, o fenômeno do envelhecimento da força de trabalho afetará, mais cedo ou mais tarde, todas as regiões da Europa. O índice de crescimento para o grupo de 60-64 anos alcançará de 105\% a 160\% entre 1995 e 2015. Regiões da Bélgica, França, Finlândia, Irlanda e Holanda mostraram a mais forte taxa de envelhecimento entre a população em idade de trabalho. Relacionado a isso está o fato de que, como resultado das mudanças demográficas nos países da UE, a população economicamente ativa provavelmente diminuirá nas próximas duas décadas. Apesar dos Estados Unidos serem mais "jovens" que a UE, o número de trabalhadores idosos e de meia-idade está crescendo também. Ao mesmo tempo, a força de trabalho mais jovem cresce vagarosamente.

Deste modo, tanto nos EUA quanto na UE, à medida que a força de trabalho envelhece, as empresas precisarão empregar uma porção maior de trabalhadores com mais de 50 anos. Empregadores terão que encontrar modos de reter trabalhadores mais velhos e mantê-los produtivos por mais tempo, pois a oferta de trabalhadores mais novos não será suficiente para repor a geração dos baby boomers ${ }^{2}$ que se aposentarão. Assim, uma questão-chave para o futuro é: com quanto sucesso os empregadores podem se ajustar a esta mudança sem precedentes na composição de suas forças de trabalho? Este é um ponto ao qual retornarei mais adiante.

\subsection{O Paradoxo Idade/Trabalho}

Talvez o envelhecimento da força de trabalho por si só não seja suficiente para alcançar o topo da agenda política. Contudo, a combinação do envelhecimento da força de trabalho unida ao desenvolvimento de uma cultura européia de saída precoce criou um imperativo para ações políticas. Conseqüentemente, é o paradoxo idade/trabalho o maior incentivo para ações: enquanto a expectativa de vida aumentou cerca de dez anos desde os anos 50, a participação de homens mais velhos na força de trabalho caiu de quase $80 \%$ para aproximadamente $30 \%$. Atualmente, apenas um terço das pessoas entre 55 e 64 anos são economicamente ativas.

\footnotetext{
2 Nota do revisor: após a Segunda Guerra Mundial, nos anos 50 e 60 do século XX, houve um forte aumento da taxa de natalidade em muitos países, o chamado baby boom. Esta geração populosa entrará na próxima década na fase de aposentadoria.
} 
Deste modo, a característica dominante das experiências no mercado de trabalho de trabalhadores mais velhos na UE é o constante declínio em suas taxas de emprego durante os últimos 20 anos. O compasso da queda varia consideravelmente de país para país, especialmente entre os do norte e os do sul da UE, mas a tendência é persistente e manifesta. Sabe-se que os principais fatores por trás deste crescimento nas saídas precoces estão relacionadas com a demanda e, especificamente, recessão, desemprego e demissão (WALKER, 1985; TRINDER, 1989; KOHLI, REIN, GUILLEMARD \& VAND GUNSTEREN, 1991; LACZKO \& PHILLIPSON, 1991). De fato, discutiu-se que a "aposentadoria precoce", ou a retirada do mercado de trabalho que causa diretamente um aumento no desemprego, é melhor compreendida como uma forma de desemprego do que de aposentadoria (CASEY \& LACZKO, 1989).

Os EUA também experimentaram a saída precoce na mesma proporção que a UE nos anos 70 e 80 . De fato, o nível de participação de homens entre 60 e 64 anos na força de trabalho começou a cair na década de 50 e, entre aqueles com idades entre 55 e 59 anos, começou a cair nos anos 60 (KOHLI, REIN, GUILLEMARD \& VAND GUNSTEREN, 1991). Nos dias de hoje, entretanto, a demanda de trabalho continuou alta. Além disso, "empregos-ponte", aqueles ocupados entre o fim de uma longa carreira de trabalho e a aposentadoria, são mais comuns nos EUA do que na UE. Alguns políticos da UE invejam o alto nível de criação de empregos dos Estados Unidos, mas, na verdade, nas taxas totais de emprego para o grupo de 25 a 54 anos a UE leva vantagem sobre os EUA. Contudo, existem grandes diferenças no respeito ao emprego entre trabalhadores mais jovens e mais velhos. O grupo com idade mais avançada representa um quarto da diferença nos índices de empregos entre os EUA e a UE. Em outras palavras, um mercado de trabalho em ascensão levanta, como o mar, todos os barcos. Além disso, o Ato Contra a Discriminação Etária no Emprego de 1967 tornou os empregados americanos mais atentos à questão da discriminação que suas contrapartes européias.

$\mathrm{Na}$ UE, um dos principais mecanismos que conduzem às saídas precoces pelos últimos vinte anos têm sido as políticas públicas. Medidas como a pré-aposentadoria na Dinamarca e Alemanha, compensação por invalidez na Holanda e Suécia e o Plano de Quitação do Emprego no Reino Unido incentivaram ativamente a tendência em prol da saída precoce da força de trabalho, algumas vezes com o sentido de substituir trabalhadores mais 
velhos por mais novos. Em outras palavras, os políticos consideraram os trabalhadores mais velhos como uma solução parcial para o desemprego, particularmente suportando o desemprego dos jovens - mas eles estavam errados, e a política não surtiu efeito (obviamente este era apenas um dos elementos de uma política geral de redução de estoque de trabalho, que também incluía ações para contratar o influxo de jovens recrutas do mercado de trabalho). Além disso, a saída precoce foi uma solução favorecida tanto pelos empregadores, que poderiam reduzir o contingente de suas forças de trabalho ou rejuvenescê-las com assistência de subsídios públicos, quanto pelos sindicatos, que poderiam negociar pacotes de aposentadorias precoces para seus membros, muitos dos quais estavam ansiosos para deixar a força de trabalho. Por exemplo, o plano nacional de aposentadoria voluntária (Voluntary Early Retirement Plan - VUT), na Holanda, foi criado por um acordo coletivo.

O final dos anos 70 e início dos anos 80 , conseqüentemente, testemunharam um alto nível de consenso entre as partes por trás da política de saída precoce. Isso não significa que os governos intervieram em seus mercados de trabalho nacionais na mesma medida - de fato, diferenças no nível de tais intervenções caracterizam a disposição dos empregadores agora em aceitar o abandono da política de saída precoce - mas a larga aceitação da saída precoce era notável. Planos públicos de aposentadorias precoces eram largamente assinados em todos os países da Europa em que estavam disponíveis. Eles não foram a única razão para trabalhadores mais velhos deixarem o emprego, mas ajudaram a criar um panorama propício para que isso ocorresse.

Também nos EUA a política pública subsidiou o processo de saídas precoces, por exemplo, por oferecer vantagens de imposto aos empregadores cujos sistemas de pensões "permitiam e encorajavam" aposentadorias antes dos 62 anos. Mesmo planos de aposentadorias individuais permitiam a retirada de fundos sem penalidade de taxas com 59 anos e meio.

Infelizmente, a política de saídas precoces deixou conseqüências imprevistas e, retrospectivamente, pode ser vista como uma solução de curto prazo para o urgente problema econômico do desemprego, cujos custos sociais e econômicos nunca foram debatidos abertamente (WALKER, 1982) e que, com a veloz mudança das circunstâncias, parecem crescentemente anacrônicos. Em primeiro lugar, o aumento da saída precoce da força de trabalho diminuiu o papel do sistema previdenciário público como regulador- 
chave da aposentadoria e, por meio disso, aumentou a precariedade e a exclusão de muitos trabalhadores mais velhos do mercado de trabalho (GUILLEMARD, 1993). Além disso, uma vasta gama de benefícios e mecanismos institucionais ad hoc foram adicionados aos sistemas de proteção social nos estados do norte da UE para facilitar a saída precoce e mediar o crescente intervalo entre emprego e aposentadoria. Contudo, esses benefícios não cobrem todos os trabalhadores mais velhos e muitos são deixados com quase nada além da assistência social.

Em segundo lugar, o crescimento desmedido das saídas precoces reforçaram a desvalorização dos trabalhadores mais velhos no mercado de trabalho. Como o limiar de idade foi diminuído para permitir rotas de saída do emprego, isto teve conseqüências significativas para os trabalhadores que envelheciam no mercado de trabalho, uma vez que provavelmente afetaria a percepção dos empregadores sobre a idade em que os trabalhadores são considerados "velhos demais" - uma questão para a qual eu retornarei.

Em terceiro lugar, para muitas empresas isso significa perda de experiência, habilidades e know-how. Também desviou a atenção do desenvolvimento de estratégias holísticas de recursos humanos designadas a prevenir o envelhecimento no trabalho, e, em alguns países, aumentou as contribuições dos trabalhadores na segurança social. As conseqüências custosas da saída precoce não podem ser descritas como imprevistas, mas nota-se que o ônus não foi plenamente antecipado pelos empregadores nem pelos governos dos países da UE.

Além disso, apesar de não serem os únicos fatores, as políticas públicas desempenham um papel significativo na criação do paradoxo idade/emprego, o que sugere que elas possuem um papel igualmente importante na promoção do envelhecimento ativo.

\subsection{Custos da Proteção Social}

As pressões principais por trás das recentes mudanças nas políticas acerca de trabalhadores idosos nos diferentes países da UE são políticas e econômicas e, particularmente, o desejo de limitar os custos de segurança social associados com saída prematura e, conseqüentemente, com pensões públicas. Este é o fator proeminente na Bélgica, Franca, Grécia e Itália, e também na Finlândia e Suécia, e é um fator de grande importância em todos 
os outros países na pesquisa de Barreiras Etárias, que cobriu nove países membros da UE (WALKER, 1997). Os políticos estão cientes de que a escala de saídas precoce na Europa é insustentável, especialmente a partir de 2005, quando a geração pós-baby boom chegará aos 55 anos. Contudo, em cada país da UE existem aspectos específicos para a discussão e suas prescrições políticas. Na França, por exemplo, o desejo de limitar os custos das pensões levaram a ações governamentais, tanto para restringir a freqüência de saídas precoces, oferecendo planos de aposentadorias parciais, quanto para reformar o sistema de previdência pública, visando prolongar o tempo de trabalho. Na Suécia, caminhos generosos para a saída de trabalhadores foram previamente limitados ou fechados, e as empresas foram incentivadas a se responsabilizarem por contrabalançar a saída do mercado de trabalho. Apesar disso, muitos trabalhadores suecos ignoraram estes apelos e a saída precoce continuou.

A ênfase nos diversos fatores subjacentes à recente mudança política, afastando-se da saída precoce e, algumas vezes, indo na direção de políticas pró-ativas sobre idade e emprego, parece ser um pouco diferente em três dos nove países pesquisados da UE - Alemanha, Holanda e o Reino Unido. $\mathrm{Na}$ Alemanha, dois fatores estão conduzindo a política - apesar de não terem os mesmos pesos. Por um lado nota-se que uma ação imediata é necessária para desenvolver políticas trabalhistas e iniciativas de treinamento para, posteriormente, prevenir futuras faltas de trabalhadores resultantes de mudanças demográficas. Por outro lado, e com muito mais influência, estão as pressões políticas e econômicas para reduzir os gastos com pensões, o que resultou, em 1992, na reforma da legislação, aumentando a idade mínima. Em 1996, o governo alemão aboliu o plano de previdência que permitia aos homens se aposentarem aos 60 anos, após, pelo menos, um ano de desemprego. Um plano de trabalho de meio-expediente para trabalhadores idosos foi apresentado em seu lugar, mas especialistas vêem pequenas chances para sua implantação em nível industrial. Simultaneamente, decidiu-se aumentar a idade da previdência de 63 para 65 para homens cinco anos mais cedo do que era previsto na reforma de 1992, e isto entrou em vigor em 2001. Como efeito dessa extensão da vida de trabalho, aumentará, futuramente, a necessidade de promoções entre trabalhadores idosos. Nos casos da Holanda e do Reino Unido há um fator normativo extra, de menor importância, por trás das novas orientações políticas. Seguindo as campanhas de grupos de mulheres, negros e minorias étnicas, crescem os casos em que organizações 
de idosos em geral, e particularmente de trabalhadores idosos, protestam contra discriminações pela idade e exigem igual acesso às oportunidades de trabalho (MCEWEN, 1992).

Portanto, os fatores-chave que criaram uma nova perspectiva de política sobre saída precoce e idade e emprego são as pressões políticas e econômicas nacionais para reduzir gastos na segurança social, especialmente na área previdenciária, pressões que são exacerbadas pela recessão e alto desemprego, presentes e previstas faltas de abastecimento de mão de obra resultantes principalmente de mudanças demográficas e do crescente perfil da discriminação de idade em alguns países. Em alguns países, fatores adicionais são relevantes, como a perda de experiência e know-how com a partida prematura de trabalhadores mais velhos (Bélgica e França), e as conseqüências não intencionais da saída precoce e do envelhecimento do mercado de trabalho interno (Holanda). Ênfase excessiva sobre planos de aposentadoria precoce em alguns países liberaram os empregadores da responsabilidade de analisar a relação entre idade e carreira e do desenvolvimento de ações positivas $^{3}$ para trabalhadores que envelhecem (WALKER, 1997).

A Europa se atrasou em relação aos Estados Unidos quanto ao momento da mudança política contra a saída precoce. Como foi visto, ela chegou recentemente na UE (principalmente nos anos 90), mas, nos EUA, já em 1983 foram tomadas medidas para restringir as saídas precoces, como, por exemplo, aumentando a "penalidade" por aposentar-se antes dos 65 anos e concedendo incentivos para adiar a aposentadoria (KOHLI, REIN, GUILLEMARD \& VAND GUNSTEREN, 1991).

Atualmente, a política nos países da União Européia e nos Estados Unidos está concentrada na terceira idade (50-74 anos), mas alguns políticos também estão atentos aos custos da saúde e do cuidado causados por dependência na quarta idade - custos que se elevarão substancialmente com o envelhecimento da geração baby-boom, a menos que ações sejam tomadas. Existe uma ligação evidente entre saúde e atividade e, além disso, as políticas devem também encorajar a atividade não-remunerada na idade avançada.

\footnotetext{
3 Nota do revisor: "ações positivas" é uma tradução de "good practice", conceito desenvolvido por Walker para descrever práticas e ações consideradas positivas, não somente para trabalhadores mais velhos, mas pensando nas condições de vida e de trabalho dos recursos humanos tendo em vista o processo de envelhecimento (veja, WALKER, Alan. Managing an Aging Workforce: a guide to good practice. Luxemburgo: European Foundation for the Improvement of Living and Working Conditions, 1999).
} 


\subsection{Suportando Mudanças a Nível Industrial}

O foco para o ajuste e gerenciamento etário no envelhecimento da força de trabalho deve ser a organização individual, empresa ou indústria. Recentes pesquisas européias revelaram alterações nas posturas dos empregadores para com trabalhadores mais velhos. Alguns empregadores estão reavaliando as conseqüências da saída precoce. Ela está sendo vista por alguns como um desperdício de experiência e recursos humanos, e de investimentos que foram feitos na força de trabalho. Outros vêem papéis para trabalhadores mais velhos no treinamento de pessoas mais jovens ou na prevenção de falta de profissionais capacitados. Na pesquisa pan-européia, patrocinada pela Fundação Européia, encontramos 160 exemplos de ações positivas da utilização de trabalhadores mais velhos, indo de pequenas mudanças em anúncios de oferta de emprego, até expansivos programas de conscientização (WALKER \& TAYLOR, 1998). No Reino Unido, alguns empregadores chegaram a construir um projeto para empregar esse grupo, moldado sobre cinco pontos: o retorno do investimento em capital humano; prevenção de falta de profissionais capacitados; maximização do potencial de recrutamento; responder às mudanças demográficas; e promover a diversidade da força de trabalho (WALKER, 1995; 1997).

Apesar desses claros e presentes sinais de mudança, ações positivas no emprego de trabalhadores mais velhos permanecem a exceção. $\mathrm{O}$ progresso é lento e casual, e geralmente depende da existência de um campeão no interior da empresa para persistentemente promover o debate ou uma iniciativa específica. Desta forma, a resposta para a questão crítica levantada anteriormente de com quanto sucesso as empresas estão se ajustando ao envelhecimento da força de trabalho é: poucas empresas na UE conseguiram um grande sucesso, mas a maioria ainda tem que enfrentar francamente o debate. Os políticos em alguns países da UE reconheceram a necessidade de apoiar a mudança que se instaura em nível industrial.

\subsection{O Papel da União Européia}

Em quinto lugar, é importante saber que a UE por si própria tem desempenhado um importante papel em incitar as mudanças na política acerca do envelhecimento ativo. O debate do envelhecimento da força de trabalho e o problema da discriminação contra trabalhadores mais velhos se deslocaram 
para o topo da agenda política européia na última década. Quando o Observatório Europeu Sobre Envelhecimento e Pessoas Idosas foi fundado, em 1990, ele identificou idade e emprego como uma das quatro áreas-chave políticas que deveria monitorar (as outras seriam renda e padrões de vida, saúde e assistência social e integração social)(WALKER, GUILLEMARD \& ALBER, 1991; 1993). Conseqüentemente, em 1993, o Ano Europeu de Pessoas Idosas e Solidariedade Entre Gerações foi parcialmente focado nesta questão, com a publicação do primeiro relatório importante sobre discriminação etária contra trabalhadores mais velhos na Comunidade Européia (DRURY, 1993). Adicionalmente, a inspeção do Eurobarômetro, especialmente comissionada para o Ano Europeu, revelou, pela primeira vez, a amplitude da percepção pública da discriminação etária (WALKER, 1993). Ao final do Ano Europeu, os trabalhadores mais velhos foram considerados, tanto em documentos da Câmara, quanto do Parlamento, uma área de prioridade. Uma longa série de pesquisas e artigos políticos da $\mathrm{DGV}^{4}$ sistematicamente chamaram atenção para a importância do envelhecimento da força de trabalho.

No meio de 1993, a Comissão produziu o Artigo Branco, Crescimento, Competitividade e Emprego, que foi aprovado pelos chefes de estado como base para futuras ações da UE. O Artigo Branco definiu como importantes objetivos estratégicos uma força de trabalho mais flexível e práticas de emprego para posteriormente enfrentar os desafios de uma competição global. Ele tornou-se o primeiro reconhecimento público da UE das implicações do envelhecimento da força de trabalho, apesar de não propor nenhuma ação específica para trabalhadores mais velhos. O Artigo Branco de 1994, Política Social Européia: um caminho para a União, não mencionou especificamente os trabalhadores mais velhos, mas se referiu à necessidade econômica das pessoas mais velhas de fazerem uma contribuição ativa à sociedade.

Em dezembro de 1994, no encontro do Conselho Europeu em Essen, os chefes de governo e Estado confirmaram a luta contra o desemprego como uma missão superior para a União Européia e como o objetivo central da política econômica. A Declaração do Conselho Europeu salientou cinco áreas-chave para aumentar a oferta de empregos, sendo que o quinto deles, promovendo medidas para ajudar grupos particularmente atingidos pelo

4 Nota do revisor: DGV se refere à Comissão Européia, Diretoria Geral para Emprego e Assuntos Sociais. 
desemprego, declarava que "deve ser prestada especial atenção à difícil situação de mulheres desempregadas e dos trabalhadores mais velhos". A Presidência Francesa do Conselho Europeu, em junho de 1995, viu a primeira declaração política, em nível da União Européia, da necessidade de ações especiais nesse campo. A Resolução Sobre Emprego de Trabalhadores Mais Velhos enfatizava dois princípios-chave:

a) a necessidade de redobrar esforços para adaptar treinamento profissional e condições de trabalho às necessidades dos trabalhadores mais velhos;

b) medidas devem ser tomadas para prevenir a exclusão dos trabalhadores mais velhos do mercado de trabalho e trabalhadores mais velhos devem ter recursos financeiros suficientes.

A Resolução propunha específicas ações a serem tomadas pelos governos nacionais e/ou parceiros sociais, incluindo crescente conscientização entre empregadores das conseqüências de tornar trabalhadores mais velhos obsoletos, promovendo a reintegração de trabalhadores mais velhos desempregados e eliminando possíveis barreiras legislativas para o emprego de trabalhadores mais velhos, embora não sejam obrigatórias nos países da UE. A Resolução também conclamou o Congresso Europeu a promover a troca de informações e ações positivas a respeito do emprego de trabalhadores mais velhos pela UE (para informações mais aprofundadas sobre ações da UE com trabalhadores mais velhos, vide DRURY, 1995).

O Conselho Europeu enfatizou, em 1996 e 1997, o desemprego a longo prazo e o desemprego dos jovens, mas os Planos de Ações Nacionais (National Action Plans - NAPs) entraram em acordo em Amsterdã, e o subsequente Encontro de Cúpula sobre Trabalho, em Luxemburgo, em novembro de 1997, forneceu a estrutura para o desenvolvimento e avaliação de políticas trabalhistas ativas. O Tratado de Amsterdã de 1997 (Artigo 13) deu poderes para que a Comissão propusesse ações contra a discriminação. O Encontro de Cúpula do Conselho Europeu em Cardiff, em junho de 1998, novamente enfatizou a necessidade de dar mais atenção aos trabalhadores mais velhos como prioridade para desenvolver uma força de trabalho competente e adaptável, e a importância de afastar a discriminação do mercado de trabalho. Em outubro de 1998, o Encontro de Cúpula de Viena também destacou a questão do envelhecimento da força de trabalho. Os Guias do Emprego de 1999 para os NAPs incluía uma referência para a necessidade de encorajar trabalhadores mais velhos a participarem ativamente no mundo 
de trabalho e para a importância de oportunidades de aprendizagem ao longo da vida para os trabalhadores mais velhos.

A Presidência Finlandesa de 1999 garantiu que esta questão estava no topo da agenda da EU e, além disso, os Guias de Emprego de 2000 e 2001 incluíam explicitas referências ao envelhecimento dos trabalhadores. Por exemplo, o Guia de 2001 incluía um artigo intitulado Desenvolvendo uma Política para o Envelhecimento dos Trabalhadores, que visava "aumentar as capacidades de, e iniciativas para, os trabalhadores mais velhos manterem-se no mercado de trabalho o maior tempo possível" (EUROPEAN COMMISSION, 2001).

\section{Política é Importante (porém Geralmente Passiva)}

Estas são os principais motivos de por que o envelhecimento ativo está se deslocando para o topo da agenda política da UE e por que as políticas públicas estão começando a levar a sério a questão do envelhecimento da força de trabalho. A competitividade no setor privado e a eficiência no setor público, no futuro, basear-se-ão, cada vez mais, na performance e produtividade de uma mão de obra envelhecida. Em outras palavras, um grande negócio depende da manutenção da capacidade de trabalho entre trabalhadores mais velhos e sua utilização eficiente por parte dos empregadores. Entretanto, existe o perigo de que, como em sindicatos individuais, os governos optem por uma solução relativamente passiva, de custos baixos e curto prazo.

Recentemente, houve uma mudança radical nas posturas oficiais para com a saída precoce na maioria dos países da UE. Muitos deles, com planos de aposentadoria precoce ou programas que a facilitavam, tomaram medidas para limitar ou reduzir o acesso a eles - Áustria, Bélgica, Finlândia, França, Alemanha, Itália, Holanda e Espanha.

Isto não significa que o envelhecimento ativo seja um assunto de maior importância na agenda política de todos os países. Por exemplo, entre todos os nove países membros da UE representados na pesquisa de Barreiras Etárias (WALKER, 1997), é possível distinguir dois grandes grupos. Na Bélgica, Finlândia, Alemanha, Holanda e no Reino Unido a questão tem um perfil político de grande importância, enquanto nos países restantes (Grécia, Itália e Suécia) ele parece representar uma prioridade menor. Ainda no primeiro grupo a questão do envelhecimento ativo tem um perfil particularmente importante na França, Finlândia, Alemanha, Holanda e no Reino Unido. 
Em, 1993, o Ministro do Trabalho inglês patrocinou pessoalmente uma grande campanha de publicidade voltada aos empregadores, sensibilizando-os para a discriminação etária e para encorajá-los a recrutar pessoas mais velhas. Isto foi intensificado no Novo Governo do partido Labour na forma de iniciativa de diversificação etária e através da publicação do Código de Práticas no Emprego de Trabalhadores Mais Velhos. O governo holandês adotou uma postura ainda mais pró-ativa e fundou a Agência de Discriminação Etária para destacar essa questão. Na França, há um debate corrente sobre aposentadoria gradual e novas propostas no parlamento nacional. Na Finlândia existe um Programa Nacional para Trabalhadores mais velhos. Na Alemanha, a Comissão parlamentar "Mudança Demográfica", instituída pelo Bundestag (Parlamento Federal Alemão), enfatizou a necessidade de encorajar trabalhadores mais velhos a continuarem no emprego.

Observando os Estados Unidos, parece haver muito poucas iniciativas voltadas à extensão da capacidade de trabalho e à manutenção da produtividade de trabalhadores mais velhos. Por exemplo, um estudo de mais de 400 empresas descobriu que quase nenhuma ajustou seus estilos de treinamento para levar em conta os diferentes requisitos para a aprendizagem de trabalhadores mais velhos (BARTH, MCNAUGHT \& RIZZI, 1993). O Departamento de Trabalho Americano patrocinou pesquisas sobre ações positivas no treinamento organizado pelos empregadores, mas bem poucas focavamse em trabalhadores maios velhos. Entretanto, surgiram iniciativas muito recentes no treinamento em informática para trabalhadores mais velhos, como o Polegar Verde - uma agência de emprego e treinamento servindo pessoas residentes em áreas rurais, apoiada pelo Departamento do Trabalho e pela Microsoft, e o Centro Nacional de Carreira do Trabalhador Idoso, em Washington, DC.

As falhas das respostas passivas e de curto prazo para o envelhecimento da força de trabalho (um caráter de longo prazo dos mercados de trabalho da UE) são três. Primeiro, políticas passivas que centram-se na proteção social estão destinadas, na melhor das hipóteses, a confirmar a discriminação etária e, na pior, encorajá-la - como foi o caso na UE entre os anos 70 e 80 . Segundo, se as políticas públicas iniciam e terminam no caminho para a saída precoce e o aumento da idade para aposentadoria (i.e., como uma política monodimensional conduzida pela Fazenda), elas aumentarão a exclusão econômica e social vividas pelos trabalhadores mais velhos. Além disso, na maioria dos países da UE, há um duradouro "período de limbo" 
entre a idade em que os trabalhadores deixam o trabalho remunerado e a idade para aposentadoria. Para alguns, este é um período de severa necessidade financeira, desgaste psicológico e falta de esperança. O terceiro defeito das respostas passivas, de curto prazo para o envelhecimento da força de trabalho, é que elas tendem somente a remediar, e não solucionam nem previnem o problema subjacente. A questão-chave é a manutenção da capacidade de trabalho. Paradoxalmente, o trabalho por si só é tanto um grande responsável por doenças e incapacidades quanto uma importante fonte de ganho de saúde, em termos de atividade, auto-estima e contato social. Mas, mesmo se os aspectos de incapacitação e produção de doenças pelo trabalho sejam reduzidos, o envelhecimento cronológico continuará a ser acompanhado de envelhecimento físico e mental. A menos que os fatores que limitam a capacidade de trabalho sejam amenizados, bem como combatidas as barreiras para o emprego, então não será possível que o envelhecimento ativo ou produtivo seja alcançado em larga escala. Colocando em outras palavras: se a saúde e a capacidade de trabalho dos trabalhadores for mantida, eles terão mais vontade e estarão mais aptos a estender seu tempo de trabalho. Além disso, uma abordagem de políticas públicas mais ativas é necessária para encorajar o envelhecimento ativo.

Até agora, pois, a principal resposta para o envelhecimento da força de trabalho nos Países Membros da UE é, preferencialmente, passiva, centrada para as saídas precoces subsidiadas e, em alguns casos, o encorajamento de empregos de meio expediente. Apesar das evidências de que as políticas públicas podem ter um significativo impacto no comportamento do mercado de trabalho - por exemplo, descobrimos que mudanças nas políticas públicas foram um dos três fatores-chave por trás do desenvolvimento de ações positivas no combate às barreiras etárias, apenas uma minoria de Países Membros são pró-ativos nessa questão. A maioria dos Países Membros estão sendo reticentes a respeito de políticas sobre envelhecimento ativo e envelhecimento da força de trabalho.

Uma idéia sobre a extensão (e a necessidade) das ações de políticas públicas pode ser vista na Tabela 1 (baseada na análise pela Organisation for Economic Co-operation and Development-OECD). A linha base (a) presume que as taxas de participação por idade permanecem como nos níveis atuais, enquanto o cenário de aposentadoria posterior (b) considera que a recente tendência entre os homens de aposentadoria precoce é revertida e que o padrão de 1995 de saídas, gradualmente retorna ao padrão de 1970 entre 2000 e 
2030. Assim como anteriormente as políticas públicas eram necessárias para encorajar a saída precoce, agora elas são necessárias para realizar as mudanças na cultura, imprescindíveis para encorajar e possibilitar que as pessoas trabalhem por mais tempo.

Tabela 1

\begin{tabular}{|c|c|c|c|c|}
\hline Países/Regiões & 1970 & 1995 & 2030 (a) & 2030 (b) \\
\hline Áustria & 31,5 & 26,6 & 36,9 & 45,3 \\
\hline Bélgica & 31,4 & 25,5 & 31,8 & 43,3 \\
\hline Dinamarca & 36,4 & 34,0 & 37,3 & 46,3 \\
\hline Finlândia & 31,5 & 34,2 & 36,9 & 44,2 \\
\hline França & 32,9 & 30,7 & 39,1 & 47,7 \\
\hline Alemanha & 33,1 & 31,5 & 40,3 & 50,4 \\
\hline Grécia & 35,3 & 33,0 & 45,0 & 54,3 \\
\hline Irlanda & 39,0 & 28,4 & 42,2 & 49,9 \\
\hline Itália & 30,5 & 29,5 & 43,0 & 50,6 \\
\hline Luxemburgo & 28,6 & 26,1 & 33,6 & 38,8 \\
\hline Holanda & 29,7 & 26,6 & 33,5 & 45,1 \\
\hline Portugal & 33,0 & 31,7 & 44,0 & 55,4 \\
\hline Espanha & 32,6 & 27,2 & 44,6 & 54,1 \\
\hline Suécia & 39,3 & 38,6 & 40,7 & 45,7 \\
\hline Reino Unido & 37,9 & 33,8 & 38,7 & 46,1 \\
\hline UE 15 & 33,5 & 30,5 & 39,1 & 47,8 \\
\hline OECD & 32,9 & 30,6 & 40,5 & 48,2 \\
\hline EUA & 27,7 & 25,0 & 28,9 & 27,9 \\
\hline Japão & 21,9 & 33,1 & 34,5 & 31,1 \\
\hline
\end{tabular}

Trabalhadores mais velhos (45+) na proporção da força de trabalho

Fonte: OECD. Disponivel em: <http:// www.oecd.org>.Acesso em: 12 maio 2006. 
4 Discriminação Etária: a barreira para o envelhecimento ativo

Antes de destacar como o envelhecimento ativo deve ser promovido, é importante reconhecer que a discriminação etária é uma barreira significativa para essa questão. Além disso, apesar da clara mudança, nos Países Membros, nas políticas em favor da saída precoce, a realidade para muitos trabalhadores mais velhos na maioria dos países da UE continua sendo a exclusão do mercado de trabalho. Em muitos países, os trabalhadores mais velhos tendem a possuir um status relativamente baixo no mercado de trabalho, experienciam a discriminação em relação à contratação e ao treinamento profissional e são desproporcionalmente representados entre os desempregados a longo-prazo (WALKER, 1997). O método mais comum de redução de custos previdenciários - aumento da idade mínima para pensão - simplesmente agrava e estende a exclusão experienciada pelos trabalhadores mais velhos.

As evidências da discriminação de idade são difíceis de identificar, pois muitas delas são escondidas e indiretas. Além disso, trabalhadores mais velhos que alegam discriminação etária são comumente acusados de usá-la como uma desculpa conveniente. De fato, quando perguntados diretamente a respeito no Eurobarômetro de 1996, muito poucas pessoas acima de 45 anos (3,3\% para homens e 3,6\% para mulheres) afirmaram ter experenciado tal discriminação nos últimos doze meses. O pequeno número de discriminações relatadas pode ser resultado da natureza indireta que a discriminação normalmente adota e do fato que ela é muitas vezes escondida daqueles que a sofrem (porque candidatos para uma vaga podem ser escolhidos para a entrevista em função da sua idade, ou pessoas podem não se candidatar pela maneira como um anúncio para uma vaga é formulado). Outras evidências indicam que se trata de um endêmica e persistente característica do mercado de trabalho europeu. Por exemplo, quando a população em geral foi perguntada sobre esta questão, a grande maioria reconhecia a existência de discriminação em função da idade.

Trabalhadores mais velhos representam uma parcela menor de novas contratações do que de emprego total. Uma recente análise da OECD mostra que, entre trabalhadores com idades entre 45 e 64 anos, a parcela de contratações vai de um quarto à metade da parcela de emprego. Enquanto isso, para trabalhadores mais jovens (entre quinze e 24 anos), ela representa mais que o dobro da parcela de emprego. Em outras palavras, muitas empresas que empregam um número significativo de trabalhadores mais velhos tendem, 
apesar disso, a não os contratar. A análise multivariativa da OECD revela que as preferências dos empregadores por candidatos mais jovens são uma das razões por que pessoas mais velhas vivenciam longos períodos de desemprego e recebem salários menores quando são re-empregadas.

Enquanto o Ato de Discriminação Etária no Trabalho de 1967, como emenda, proíbe discriminação em todos os aspectos do trabalho, incluindo treinamento, os empregadores nos EUA investem menos no treinamento de pessoas mais velhas do que de pessoas mais jovens. Assim como na UE, os trabalhadores mais velhos americanos ficam desempregados por mais tempo que os mais jovens, têm maior predisposição para serem não-empregados (i.e., fora do mercado de trabalho) e muitas vezes defrontam maiores reduções salariais ao encontrar emprego.

Nós sabemos, por estudos investigativos nacionais, que na UE os empregadores comumente guardam imagens estereotipadas dos trabalhadores mais velhos e que isso influencia as práticas de contratação, treinamento e promoções. Por exemplo, no Reino Unido, os estereótipos que apareceram com relação mais próxima com as práticas de trabalho atuais são: trabalhadores mais velhos são difíceis de treinar; não querem ser treinados; falta de criatividade; são excessivamente cautelosos; incapazes de trabalhos físicos pesados; sofrem menos acidentes; e não gostam de receber ordens de trabalhadores mais jovens. Contra estes estereótipos profundamente arraigados, as evidências científicas provam que trabalhadores mais velhos são, em média, tão eficientes em seus trabalhos quanto mais jovens - considerando, é claro, que existem variações no desempenho entre trabalhos diferentes (WARR, 1998). Um grupo mais velho tem menos acidentes e está menos predisposto a deixar uma empresa voluntariamente do que trabalhadores mais novos. O custo médio para um empregador é similar ao do grupo mais jovem.

Em suma, existe uma crescente gama de evidências em diferentes países da UE que mostram que pessoas na terceira idade são freqüentemente discriminadas no mercado de trabalho (MCEWEN, 1992; DRURY, 1993; WALKER, 1993). Discriminação etária é a antítese de envelhecimento ativo e, além disso, não será possível realizá-la em um mercado de trabalho e em uma sociedade envelhecidos. Intervenções políticas se fazem necessárias para combater esta discriminação, tanto por motivos sociais quanto econômicos. Sociais, porque cria estigma, exclusão social e nega a cidadania plena. Econômicos, porque se trabalhadores mais velhos sofrem discriminação puramente pelo fato da idade, a chance de que eles contribuam economica- 
mente lhes é negada. O envelhecimento da força de trabalho reforça os imperativos morais e econômicos para ações contra a discriminação etária. Precisamente, a forma que a ação deve tomar é uma questão para debate em cada País Membro e para a UE como um todo. Enquanto o público geral da Europa estiver preocupado, há forte apoio para legislações anti-discriminação etária e este apoio vem crescendo pelos últimos sete anos (Tabela 2).

Tabela 2

\begin{tabular}{c|c|c}
\hline Países/Regiões & $\mathbf{1 9 9 2}$ & $\mathbf{1 9 9 9}$ \\
\hline Áustria & - & 64,4 \\
\hline Bélgica & 69,8 & 69,6 \\
\hline Dinamarca & 30 & 58,2 \\
\hline Finlândia & - & 75,2 \\
\hline França & 71,5 & 72,8 \\
\hline Alemanha & 57,7 & 60,3 \\
\hline Grécia & 71,8 & 85,6 \\
\hline Irlanda & 70,9 & 81,2 \\
\hline Itália & 63,3 & 69,6 \\
\hline Luxemburgo & 60,3 & 64,4 \\
\hline Holanda & 69,6 & 83,8 \\
\hline Portugal & 83,8 & 79,4 \\
\hline Espanha & 74,0 & 77,0 \\
\hline Suécia & - & 54,8 \\
\hline Reino Unido & 72,0 & 83,0 \\
\hline EU 12 (1992/ 15 & 66,6 & 71,8 \\
\hline (1999) & & \\
\hline
\end{tabular}

Porcentagem de pessoas a favor da introdução de leis para barrar a discriminação etária

Fonte: Eurobarometer Surveys (1992/1999), veja Walker, 1999. 


\section{Uma Estratégia para o Envelhecimento Ativo}

A busca atual por uma nova abordagem para aposentadoria na Europa parte da justaposição de mudanças no emprego (particularmente no declínio do padrão de trabalhador industrial homem, no qual a maioria dos sistemas previdenciários está baseado) e o envelhecimento da força de trabalho, no contexto de uma pressão orçamentária criada por uma gama de fatores, incluindo EMU (Economic and Monetary Union - União Econômica e Monetária), desemprego e envelhecimento populacional. A idéia de aposentadoria como uma fase distinta devotada ao descanso no final da vida de trabalho está sendo minada pelas mudanças no trabalho, enquanto a cultura de saída precoce é desafiada pelo envelhecimento da força de trabalho e pelas pressões nos sistemas de previdência social. Isto começou a reviver os interesses no quarto pilar da aposentadoria - emprego - depois de um extenso período no qual a saída precoce de trabalhadores mais velhos era vista como uma das metas da política trabalhista.

Nossa recente pesquisa pan-européia sugere que todos os elementos estão posicionados para uma nova abordagem para o curso de vida na idade avançada, que substituiria exclusão e decadência por inclusão e atividade; resumindo, envelhecimento ativo. De que esta abordagem consistiria?

Primeiro, para combater a discriminação etária e encarar os desafios impostos pelo envelhecimento da força de trabalho e pelo financiamento das pensões públicas de um modo ativo, voltado para promover emprego e produtividade, os Países Membros precisam de uma estratégia compreensiva sobre envelhecimento ativo e administração etária. O termo "administração etária" pode referir-se especificamente às várias dimensões pelas quais os recursos humanos são administrados no interior das empresas, mas também, mais amplamente, para a administração geral do envelhecimento da força de trabalho de uma nação.

Quando aplicamos este conceito às organizações no projeto da Fundação Européia de Barreiras Etárias, encontramos um leque de ações positivas, abrangendo desde medidas muito limitadas a medidas mais abrangentes. Concluímos que, melhor que a postura reativa atual adotada pela maioria dos empregadores, uma administração etária integrada seria a abordagem mais eficiente. Ela deveria conter, tanto medidas preventivas (como treinamento contínuo e replanejamento de trabalho), quanto remediadoras (como treinamento especial para trabalhadores mais velhos). 
Seu foco seria na vida de trabalho como um todo, e não somente em sua etapa avançada, visando neutralizar o impacto negativo do envelhecimento no trabalho.

Enquanto a administração etária, primeiro e acima de tudo, é um problema das organizações, públicas e privadas, ela não pode ser deixada somente para os empregadores. Administração etária é uma estratégia preventiva que deve ter uma base ampla. Na verdade, eu defenderia vigorosamente que seria uma responsabilidade de todos os envolvidos nos mercados de trabalho europeus, em todos os níveis, de criar as condições nas quais as ações positivas na administração do envelhecimento da força de trabalho possam prosperar. Isso inclui os políticos europeus e nacionais, empregadores, sindicatos e mesmo os trabalhadores mais velhos.

A política pública, em níveis nacionais e na UE, tem um papel decisivo no estabelecimento do contexto externo dentro do qual as organizações desenvolverão suas próprias formas de administração etária. Como os países nórdicos, especialmente a Finlândia, demonstraram para o restante da UE, um contexto de políticas públicas que valoriza claramente o capital humano e a manutenção da capacidade de trabalho é o mais adequado a levar para políticas preventivas em nível organizacional.

A UE por si própria também tem um importante papel a desempenhar em prosseguir disseminando exemplos de ações positivas e encorajar o intercâmbio de conhecimentos entre os Países Membros.

A responsabilidade pelas ações, no entanto, não se encontram somete no topo - na UE, nos Países Membros ou dentro de organizações. Os trabahadores que estão envelhecendo (o que significa todos no mercado de trabalho, uma vez que o processo de envelhecimento é contínuo) têm, por si próprios, o dever de tirar vantagens das oportunidades disponíveis no interior das empresas ou fornecidas pelas autoridades públicas para administrar seu próprio envelhecimento e suas carreiras. Em outras palavras, administração etária é tanto uma responsabilidade individual quanto coletiva.

Uma estratégia na administração etária deve incluir ações voltadas ao combate à discriminação etária no emprego. Aumentar a idade para aposentadoria deixando sem controlar o "envelhecionismo" (ageism) é simplesmente designar os trabalhadores mais velhos à exclusão, salários baixos e, eventualmente, aposentadorias inadequadas. Como apontei, discriminação etária é a antítese de envelhecimento ativo. Educação e exortação não parecem ser suficientes para superar a discriminação etária e, além disso, a legislação tem um papel a desempenhar tanto na Europa quanto nos EUA. A extensão 
lógica de uma política contra a discriminação etária seria a abolição das aposentadorias compulsórias e ter, ao invés, idade mínima para aposentadorias. Então, incentivos poderiam ser introduzidos para encorajar as pessoas a trabalhar além do mínimo. A Suécia atualmente permite o adiamento das aposentadorias até a idade de 70 anos e o novo sistema previdenciário italiano permite $\mathrm{o}$ adiamento até 68 .

Em segundo lugar, se medidas são tomadas para estender os anos de trabalho através do aumento da idade para aposentadoria sem ações sobre o impacto do emprego na saúde, os resultados serão também exclusão e um aumento no recebimento de aposentadorias por invalidez. Se estas opções também fossem fechadas aos trabalhadores mais velhos, o impacto seria severo e injusto. Apesar de haver uma tendência em direção à redução da incidência de incapacitação na idade avançada e apesar de nós podermos esperar a queda do trabalho manual para minimizar o impacto de problemas de saúde relacionados com o envelhecimento (OECD, 1998), ainda assim a existência de tais problemas interfere no ajuste da data da aposentadoria de um significativo número de trabalhadores mais velhos. Parafraseando o Relatório Negro inglês, no esforço coletivo de produção, o corpo de algumas pessoas esgota-se mais rápido que o de outras (TOWNSEND \& DAVIDSON, 1982). Paradoxalmente, o trabalho é, ao mesmo tempo, uma das maiores causas de doenças e uma importante fonte de saúde, em termos de atividade, auto-estima e contato social. A menos que os aspectos de produção de enfermidades do trabalho sejam negados, a opção do envelhecimento ativo não será aberta a todos igualmente. De um modo mais otimista: se a saúde dos trabalhadores for mantida, eles terão maior vontade e capacidade de estender suas vidas de trabalho.

Novamente, uma estratégia preventiva parece ser a única realmente eficiente, e existem vários exemplos de ações positivas a esse respeito, particularmente entre os países nórdicos. Por exemplo, o Instituto Finlandês de Saúde Ocupacional opera dois programas relevantes. O Finn Age visa promover a saúde, empregabilidade e o bem-estar para aqueles acima de 45 anos, enquanto o programa "Pequeno Ambiente de Trabalho" visa encorajar pequenas empresas a adotar ações positivas voltadas para o bem-estar de todos os empregados (bem como elas mesmas). Não é preciso dizer que uma mão de trabalho saudável tende a ser produtiva, e, uma vez que elas envelhecem, os empregadores não serão capazes de rejuvenescer suas organizações tão pronta e dispendiosamente quanto fizeram no passado. 
É claro que uma estratégia para romper o vínculo entre trabalho e doença-saúde significará melhoras no status de saúde dos sucessivos coortes de aposentados. Mas um dos riscos associados com uma política de envelhecimento ativo é que ela aumenta a exclusão dos trabalhadores informais ou daqueles que já são dependentes (dependência é por si só uma fonte de pressão nos sistemas de proteção social, mas isso ultrapassa o tema deste texto). Além disso, em terceiro lugar, devemos ampliar nossa visão além do ambiente de trabalho e enfocar na prevenção da morbidade onde quer que ela ocorra, e, desse modo, estender a qualidade de vida a todos que alcançam a aposentadoria. Isso significa uma ampla abordagem de saúde pública nos Países Membros e em nível de UE, visando a prevenção de doença-saúde e de dependências. O elo entre atividade e saúde é bem conhecido, e o que se faz necessário em todos os Países Membros é um esforço centrado para encorajar estilos de vida saudáveis e um envelhecimento saudável. Como a World Health Organization (WHO) colocou, anos foram adicionados à vida, agora devemos adicionar vida aos anos. Isto certamente permitiria que as pessoas continuassem produtivas por mais tempo. Para aqueles fora do mercado de trabalho, envelhecimento ativo deveria significar cidadania ativa, incluindo o engajamento em atividades voluntárias não-remuneradas, sem excluir a ajuda e o suporte dentro da família. Finalmente, precisamos de pesquisas sobre os fatores que contribuem para a qualidade de vida na idade avançada.

Esta estratégia de promover envelhecimento ativo não apenas forneceria uma resposta ao envelhecimento da força de trabalho, mas também seria um bom avanço para aliviar as pressões nos sistema de proteção social da Europa - pela redução de custos associados à saída precoce, pela extensão da vida de trabalho e pela redução de custos com a saúde. Estaria também de acordo com as aspirações dos trabalhadores mais velhos por mais flexibilidade na aposentadoria e ajudaria a aumentar e estender a qualidade de vida dos mais velhos na aposentadoria. Ela tem as características de uma idéia daquelas para qual o tempo chegou.

\section{Conclusão}

Este artigo enfatizou a necessidade urgente de políticas públicas ativas na preparação para o envelhecimento da força de trabalho e para reduzir os custos de previdência social, e destacou as deficiências de abordagens 
principalmente passivas e reativas, tanto em nível industrial, quanto em nível nacional. Não há dúvidas que os Países Membros da UE começaram a cuidar do paradoxo idade/emprego, mas principalmente se restringindo a subsídios para saída precoce. Recentes estudos europeus mostram também que uma minoria de organizações já está lidando com formas para se ajustar ao envelhecimento da força de trabalho. $\mathrm{O}$ fato de que aqueles na vanguarda incluem algumas das autoridades públicas e companhias comerciais mais prestigiadas da Europa indica a importância desta questão. Além disso, nossa pesquisa ilustrou um número de maneiras muito práticas pelas quais as outras organizações podem administrar o envelhecimento de suas forças de trabalho de modo mais eficiente. Existem também sinais nas mudanças de postura entre os parceiros sociais.

Há, em outras palavras, uma singular janela de oportunidades na Europa para assegurar que o envelhecimento da força de trabalho não limite o potencial de trabalho dos indivíduos envolvidos nem a competitividade econômica das empresas. O que se faz necessário é uma estratégia em nível da União Européia para um envelhecimento ativo. Refletindo as diferenças nacionais na política e nos mercados de trabalho, esta estratégia seria designada para reforçar e estender o desenvolvimento de ações positivas já iniciadas, aqui e ali, e impermeabilizar todos os atores-chave na prevenção dos efeitos negativos do envelhecimento no trabalho e vice-versa, do trabalho no envelhecimento. Visaria, também, estender a saúde e a atividade na idade avançada. Tal estratégia permitiria à UE responder eficientemente ao envelhecimento da força de trabalho, e também começaria a tornar envelhecimento ativo uma realidade.

\title{
OLDER WORKERS AND ACTIVE AGING IN THE EUROPE
}

\begin{abstract}
This article emphasises the urgent need for active public policies in preparation for workforce ageing and to reduce social protection costs. The EU Member States have begun to address the age/employment paradox, but proposals are mainly limited to curtailing early exit subsidies. Recent European research shows that only a minority of organisations are already leading the way in adjusting to workforce ageing, but among them are some of Europe's
\end{abstract}


most prestigious commercial companies and major public authorities. Moreover, our research has illustrated a number of very practical ways in which other organisations can mange their ageing workforces more effectively. There are signs too of changing attitudes among the social partners. So we can say that there is a unique window of opportunity in Europe to ensure that workforce ageing does not limit either the employment potential of the individuals involved or the economic competitiveness of enterprises. What is required is an EU-wide strategy for active ageing extending the development of good practice already underway, here and there. Keywords: Ageing. Older Workers. Public Policy.

\section{REFERÊNCIAS}

BARTH, Michael C.; MCNAUGHT, William; RIZZI, Philip. Corporations and the Aging Workforce. In: MIRVIS, Philip H. (Ed.). Building the Competitive Workforce: investing in human capital for corporate success. New York: Riley, p.156-200, 1993.

CASEY, Bernard; LACZKO, Frank. Early Retired or Long Term Unemployed. Work, Employment and Society, London, v. 3, n. 4, p. 509-526, 1989.

DRURY, Elizabeth. (Ed.). Age Discrimination Against Older Workers in the European Community. London: Eurolink Age, 1993.

DRURY, Elizabeth. Older Workers and Labour Market Programmes and Policies in the European Union. Dublin: European Fundation, 1995.

EUROPEAN COMMISSION. The Employment Guidelines for 2001. Official Journal of the European Communities, Luxemburgo, v. 44, p. 39, jan. 2001.

GUILLEMARD, Anne-Marie. Older Workers and the Labour Market. In: WALKER, Alan; GUILLEMARD, Annie-Marie; ALBER, Jens. Older People in Europe: social and economic policies. Bruxelas: CEC, p. 35$51,1993$. 
KOHLI, Martin; REIN, Martin; GUILLEMARD, Anne-Marie; VAN GUNSTEREN, Herman. (Ed.). Time for Retirement. Cambridge: Cambridge University Press, 1991.

LACZKO, Frank; PHILLIPSON, Chris. Changing Work and Retirement. Buckingham: Open University Press,1991.

MCEWEN, Evelyn. (Ed.) Age: the unrecognised discrimination. London: ACE Books, 1992.

OECD. Maintaining Prosperity in an Ageing Society. Paris, 1998.

TOWNSEND, Peter; DAVIDSON, Nick. (Ed.). Inequalities in Health: the black report. Harmondsworth: Penguin Books, 1982.

TRINDER, Chris. Employment After 55. Discussion Paper, n. 166. London: National Institute for Economic and Social Research, 1989.

WALKER, Alan. The Social Consequences of Early Retirement. The Political Quarterly, London, v. 53, n. 1, p. 61-72, 1982.

WALKER, Alan. Early Retirement: release or refuge from the labour market? The Quaterly Journal of Social Affairs, London, v. 1, n. 3, p. 211-229, 1985.

WALKER, Alan; GUILLEMARD, Annie-Marie; ALBER, Jens. Social and Economic Policies and Older People. Bruxelas: EC Commission, 1991.

WALKER, Alan. Age and Attitudes. Bruxelas: EC Commission, 1993.

WALKER, Alan, GUILLEMARD, Annie-Marie; ALBER, Jens. Older People in Europe: Social and Economic Policies. Bruxelas: EC Commission, 1993.

WALKER, Alan. Investing on Ageing Workers: a framework for analysing good practice in Europe. Dublin: European Foundation for the Improvement of Working and Living Conditions, 1995. 
WALKER, Alan. Combating Age Barriers in Employment: European Research Report. Dublin: European Foundation for the Improvement of Working and Living Conditions, 1997.

WALKER, Alan; TAYLOR, Philip. Combating Age Barriers in Employment: a European portfolio of good practice. Dublin: European Foundation for the Improvement of Working and Living Conditions, 1998.

WARR, Peter G. Age, Competence and Learning at Work. In: International Workshop on Ageing and Work, 24., Bruxelas, 1998. Anais... Bruxelas: National Institute for Working Life, p. 23-62, 1998. 